J. Lake Sci.(湖泊科学), 2009, 21(1): 77-83

http://www.jlakes.org. E-mail: jlakes@niglas.ac.cn

(C2009 by Journal of Lake Sciences

\title{
利用泥质岩硼含量重建过去湖泊古盐度和湖面变化历史*
}

\author{
伊海生, 时志强, 朱迎堂, 马 雪 \\ (成都理工大学沉积地质研究院, 成都 610059)
}

摘 要: 根据封闭湖泊古盐度与湖面变化之间具有反向变化的特点, 以沱沱河地区通天河剖面为例, 利用泥质岩的硼元素含 量作为古盐度计, 重建了青藏高原北部地区晚渐新世-早中新世湖泊沉积的古盐度变化曲线, 讨论了应用湖水古盐度变化曲 线追踪过去湖平面变化历史的适用范围和局限. 结果表明: 雅西错组上部古湖泊水体的盐度一般处于咸水湖分布区, 盐度变 化于微咸水到超咸水范围内，指示渐新世晚期气候干燥，湖平面长期处于低水位期; 但中新世早期五道梁组沉积期，高原气 候开始向湿润方向发展，湖水古盐度明显下降，湖水位快速上升。

关键词: 湖平面变化; 古盐度指标; 嗍含量; 湖泊沉积; 青藏高原; 通天河

\section{Reconstruction of paleo-salinity and lake-level fluctuation history by using boron concentration in lacustrine mudstones}

YI Haishen, SHI Zhiqiang, ZHU Yingtang \& MA Xue

(Institue of Sedimentary Geology, Chengdu University of Technology, Chengdu 610059, P.R.China)

\begin{abstract}
The relationship between lake-level changes and lake water salinities has been confirmed as a covariance in closed-basin lakes. According to this principle, lake-level fluctuation history over time can be reconstructed using quantitatively calculation of paleo-salinities in boron concentration of lacustrine mudstone deposition. In this article, boron contents in lacustrine sediments as a salinity index, examples from the Tongtianhe section in the Tuotuohe area of northern Tibetan plateau, vertical lake-level curves inferred from paleo-salinities calculation data was reconstructed during late Oligocene-early Miocene. At the same time, applicability and limitation of this method were also discussed. The results showed that the salinity of paleo-lake water was from brackish to saline water during the upper Yaxicuo Formation deposition. It indicated that late Oligocene was an arid climatic period and lake level was a long low water stand in this area. Conversely, paleo-lake water salinity obviously dropped and reflected water level rise in lower Wudaoliang Fromation. It indicated that Tibetan Plateau climate evolved to enter a humid stage in early Miocene.

Keywords: Lake level fluctuation; paleo-salinity indicator; boron content; lacustrine deposition; Tibetan Plateau; Tongtianhe
\end{abstract}

在全球变化的研究中，由于湖面变化是气候变化对湖泊影响过程的直观体现，它对自然环境变化具有 重要的指示意义, 因而受到广泛地重视 ${ }^{[1-5]}$. 对于近代和第四纪时期的湖泊体系, 古湖岸线和滨湖阶地是推 论古湖面变动的直接证据. 在这一方面国内外的地理学家和第四纪地质学家进行了大量研究工作, 积累和 发表了多方面成果，证实湖面波动对气候变化的响应极为敏感，湖水位高程变化以及湖泊面积的扩张或 收缩可以反映流域有效降水的变化, 记录区域水量平衡, 可以作为判断降水量和气候湿度状况的依据和 指标 ${ }^{[6-9]}$. 但是, 这些指示湖面波动的地貌标志, 在古代湖泊沉积中一般难以保存, 因此其应用受到限制.

在内陆干旱、半干旱地区，湖泊尤其是封闭湖泊的盐度取决于流域降水、径流和蒸发量的平衡关系, 湖水盐度与湖面变化之间呈反向相关关系 ${ }^{[10-12]}$, 因此可以利用湖水盐度随时间变化追踪湖平面变化过程. 本文应用硼元素作为古盐度计, 并以沦沱河地区通天河剖面为例, 重建了青藏高原北部晚渐新世-早中 新世湖泊沉积的古盐度和湖平面变化历史, 讨论了该方法的适用范围和局限性.

* 国家自然科学基金项目(40572077)和教育部博士点基金项目(20060616005)联合资助. 2008-04-17 收稿; 2008-06-26 收修 改稿. 伊海生, 男, 1959 年生, 博士, 教授; E-mail: yhs@cdut.edu.cn. 


\section{1 材料与方法}

\section{1 样品采集}

研究区位于青藏高原沱沱河地区，该区是青藏高原腹地新时代沉积最发育的地区之一，实验分析的 样品采自距青藏公路线约 $30 \mathrm{~km}$ 处的通天河剖面(图 1).

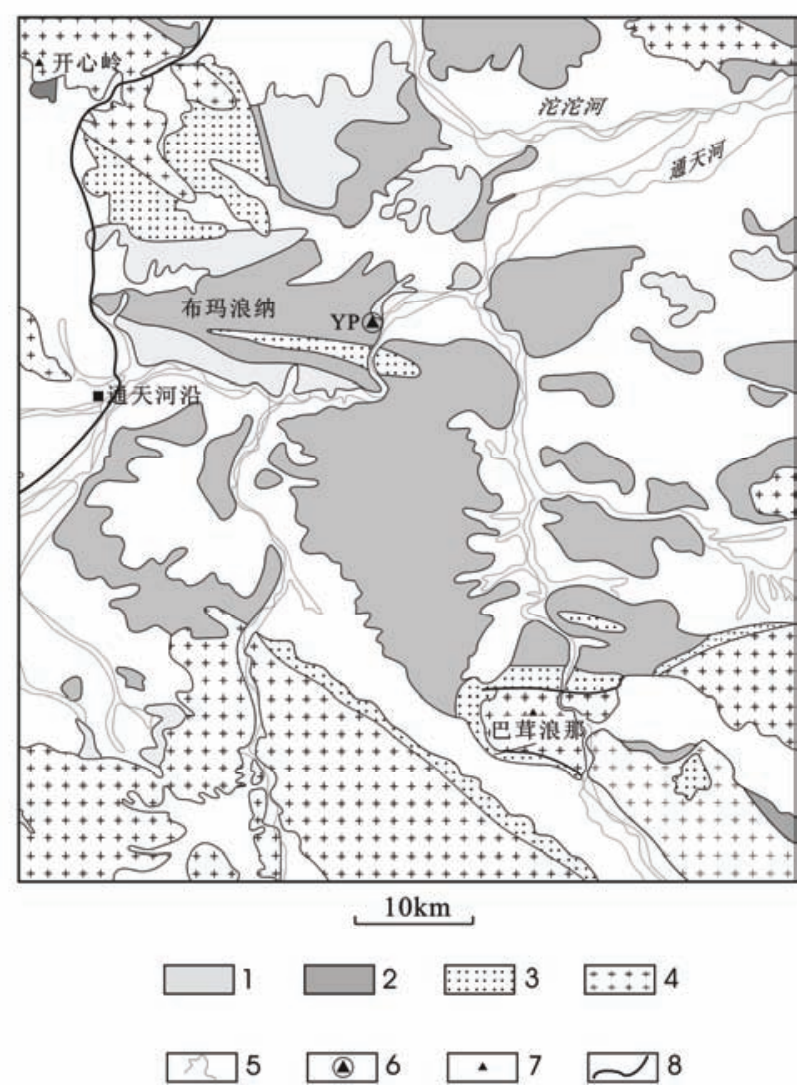

图 1 通天河地区地质简图及采样剖面位置

(1: 五道梁群; 2; 雅西错群; 3: 风火山群; 4: 前新生代地层; 5: 水系; 6: 采样位置; 7: 山峰; 8: 公路)

Fig.1 Sketch geological map of the Tongtianhe area and location of sampling section

通天河剖面是迄今为止青藏高原腹地发现的唯一不经对接的渐新统-中新统地层剖面, 其地层时代 的归属和沉积环境分析已有详细的研究工作 ${ }^{[13-14]}$. 该剖面渐新统雅西错组地层主要为黄褐色砂岩、灰色 泥岩与紫红色砂岩、粉砂岩韵律互层, 间夹灰色碳酸盐岩和黄灰色膏盐层. 中新世五道梁群为一套灰色 湖泊相钙质泥岩与灰色泥晶灰岩、黄灰色白云岩互层沉积，偶见深灰色生物碎屑灰岩薄层.二者之间以 $40 \mathrm{~cm}$ 厚的黑灰色轮藻灰岩作为地层分界的标志. 在这一地区先后开展的 1:200000 和 1:250000 区域地质 调查，根据所采集的轮藻、介形虫化石和狍粉鉴定结果，一般将雅西措组沉积时代划归渐新世，五道梁组 归属中新世.

根据沉积标志判断, 实测通天河剖面 32 层至 68 层被解释为封闭湖泊相沉积, 它们主要由单调的灰 色泥岩构成，夹薄层灰绿色、黄灰色细砂岩、粉砂岩，局部层段可见灰黑色生物碎屑灰岩、纹层状泥灰 岩和灰白色含石膏的泥岩 ${ }^{[15]}$.

样品采集选择雅西措组上部与五道梁组下部地层连续的层段进行，在界线标志层上下按 $0.5 \mathrm{~m}$ 间隔 
采样, 远离地层界线采样间距放宽到 2-5m. 采集的样品类型以泥岩为主, 次为石灰岩和白云岩样品, 采 样深度设置剖面顶界为 $0 \mathrm{~m}$, 样品在剖面上的分布如图 1 所示.

\section{2 分析测试}

实验室分析在四川省冶金地质岩矿测试中心进行, 共采集了 102 件样品进行化学分析. 全岩样品按 照常规分析流程进行了样品制备和预处理, 然后将样品分成两部分, 一组样品选用深孔电极发射光谱法 测量硼含量, 其检测限 $<2.8 \mu \mathrm{g} / \mathrm{g}$, 另一份样品采用 ICP-AES 电感塊合等离子发射光谱法测试样品中 $\mathrm{Al}$ 、 $\mathrm{K} 、 \mathrm{Na} 、 \mathrm{Ca} 、 \mathrm{Mg} 、 \mathrm{Sr} 、 \mathrm{Ba} 、 \mathrm{Fe} 、 \mathrm{Mn}$ 等元素含量. 选取代表性样品，对全岩样品和经实验分离的粘土矿 物分别进行了 X 射线衍射分析，检测了样品中的粘土矿物类型以及碳酸盐矿物的相对含量.

\section{3 古盐度计算方法}

粘土矿物吸收和固定砋的数量与溶液中砋的浓度有关, 而溶液中的硼浓度是盐度的线性函数. 综合 这两个关系, Lendergren and Carvajal 提出 ${ }^{[16]}$, 粘土矿物从水体中吸收的嗍含量与水体的盐度呈双对数关 系式，即佛伦德奇吸收方程(Freundlich adsorption isotherm):

$$
\lg B=C_{1} \lg S+C_{2}
$$

式中, $B$ 为吸收嗍含量 $\left(10^{-6}\right), S$ 为盐度 $(\%), C_{1}$ 和 $C_{2}$ 是常数, 此方程式即为利用硼和粘土矿物含量定量计 算古盐度的理论基础. 溶液中的硣一旦被粘土矿物吸收固定后, 无论其呈吸附状态存在或是进入粘土矿 物晶格, 都不会因后期物理和化学条件变化而迁移, 因而现代沉积和古代岩石记录中样品嗍含量的分析 结果可作为其最初沉积时的水体盐度标志.

Landergren 和 Carvajal ${ }^{[16]}$ 根据泥岩 $B$ 含量与水体的盐度关系等温吸收方程，提出可根据下式计算剖面 盐度变化:

$$
\lg B=0.43 \lg S+\lg 27.9
$$

式中, $B$ 为观测 $\mathrm{B}$ 含量 $\left(10^{-6}\right), S$ 为古盐度 $(\% o$ ).

Walker ${ }^{[17-18]}$ 进一步研究发现, 沉积物和沉积岩中粘土矿物含量及比例影响全岩硓含量. 一般以伊利 石对硼的吸收作用为最强, 次为蒙脱石和绿泥石, 高岭石中硼元素含量最低. 因此, 在计算古盐度时需 要考虑粘土矿物类型对硼吸收能力的差异, 建立粘土矿物与硼含量的对比关系, 必须对样品的硼含量进 行校正.

Walker 提出的盐度校正公式，以伊利石理论含钾量的 $8.5 \%$ 来换算纯伊利石中的 “调整嗍含量”，计 算校正公式为:

$$
\text { 调整 } B_{I} \text { 含量 }=8.5 \times \text { 样品 } \mathrm{B} \text { 含量/样品 } \mathrm{K}_{2} \mathrm{O} \text { 含量 }(\%)
$$

式中, $\mathrm{B}$ 和 $\mathrm{K}_{2} \mathrm{O}$ 含量指样品的实测结果 $\left(10^{-6}\right)$. 由于伊利石中的硼含量又与钾含量有关, 为了在同等条件 下进行对比, 需计算相当于 $\mathrm{K}_{2} \mathrm{O}$ 含量为 $5 \%$ 时的嗍含量, 称为 “相当硼含量”. “相当嗍含量” 是通过伊利 石粘土岩的理论 $\mathrm{K}_{2} \mathrm{O}$ 浓度与样品的实测 $\mathrm{K}_{2} \mathrm{O}$ 含量之比值对样品的硼含量进行校正, 求取相当伊利石含量 为 $100 \%$ 时的嗍含量. 根据样品 $\mathrm{K}_{2} \mathrm{O}$ 含量和计算出的调整 $\mathrm{B}$ 含量, 根据 Walker 公布的理论换算曲线, 通 过图解法求取 “相当 B 含量”. 根据 “相当 B 含量” 的计算值，可以直接判定古盐度的分布区间：正常海 相环境 “相当 B 含量” 在 300-400 之间; 小于 200 时为低盐度淡水环境; 200-300 时为微咸水; 400-800 时为超咸水; 大于 800-1000 是海洋生物生活环境盐度的上限.

Couch $^{[19]}$ 根据粘土矿物对硼的吸收比率关系，提出可以通过以下校正公式求取以高岭石含量为标准 的校正嗍含量:

$$
\text { 校正 } B_{K} \text { 含量 }=\mathrm{B} \text { 样品含量 } /\left(4 X_{i}+2 X_{m}+X_{k}\right)
$$

式中, $B_{K}$ 指以高岭石含量为标准的校正嗍含量, $X_{i} 、 X_{m} 、 X_{k}$ 分别代表样品中实测伊利石、蒙脱石和高岭石 的质量分数, 系数代表各类粘土矿物对嗍的吸收强度. 根据 Freundlich 吸收方程, 其盐度计算公式为:

$$
\lg B_{K}=1.28 \lg S_{P}+0.11
$$

式中: $B_{K}$ 为高岭石校正嗍含量 $\left(10^{-6}\right), S_{P}$ 为古盐度 $(\% o$ ). 此公式进行的样品嗍含量校正是基于样品吸附嗍的 总量与多种粘土矿物相对含量的比值关系, 适用盐度范围广 (1\%o-35\%o), 因此得到广泛应用. 


\section{2 古盐度计算结果}

对湖相沉积样品中元素化学相关性的考察, 特别是研究微量元素 $\mathrm{B}$ 与主元素 $\mathrm{Al}$ 和 $\mathrm{K}$ 等那些能够表 征岩石特征组分含量变化的关系, 就能够认识和理解湖泊沉积物中粘土矿物分布的状态, 进而对湖泊沉 积记录中粘土类型及含量变化作出解释，判定古盐度计算方法的适用性和可靠性.

$\mathrm{Al}$ 一般被认为是一个典型的陆源元素，它主要分布于粘土矿物之中，少量可能出现在粉砂质长石碎 屑中, 其含量的多少主要反映岩石组分中陆源粘土组分相对含量的高低. $\mathrm{K}$ 是伊利石粘土矿物的标志性 元素, 高岭石、绿泥石以及蒙脱石几乎不含钾, 因此样品中 $\mathrm{K}$ 的含量高低指示粘土组分中伊利石相对含 量的变化.

所分析的 102 件样品中, $\mathrm{Al}$ 与 $\mathrm{B}$ 含量之间具有线性正向相关变化, 随着 $\mathrm{Al}$ 含量增加, B 也同步增加(图 2). $\mathrm{Al}$ 与 $\mathrm{B}$ 同步变化的特点反映了 $\mathrm{B}$ 主要赋存在粘土组分之中. 从 $\mathrm{K}$ 与 $\mathrm{B}$ 含量的相关图解看, 实验测定 样品 $\mathrm{B}$ 与 $\mathrm{K}$ 含量也具有正向相关变化, 说明在粘土组分中伊利石是吸附 $\mathrm{B}$ 的主要载体(图 2). 另外, 少数 样品 $\mathrm{B}$ 与 $\mathrm{K}$ 之间没有明显的相关性，投影点分散，而且 $\mathrm{B}$ 含量偏低，推测分析样品中少量 $\mathrm{K}$ 可能以碎屑 矿物如长石等形式出现. 对样品进行的矿物成分研究，也证实了上述结论. 根据典型泥岩样品 X 射线衍 射分析, 所研究湖相沉积剖面中粘土矿物类型主要为伊利石, 相对含量占粘土组分总量 $85 \%$ 以，次为 绿泥石，未检测到高岭石和蒙脱石类粘土矿物，这就为利用伊利石中钾与硼含量的关系式计算古盐度提 供了依据.
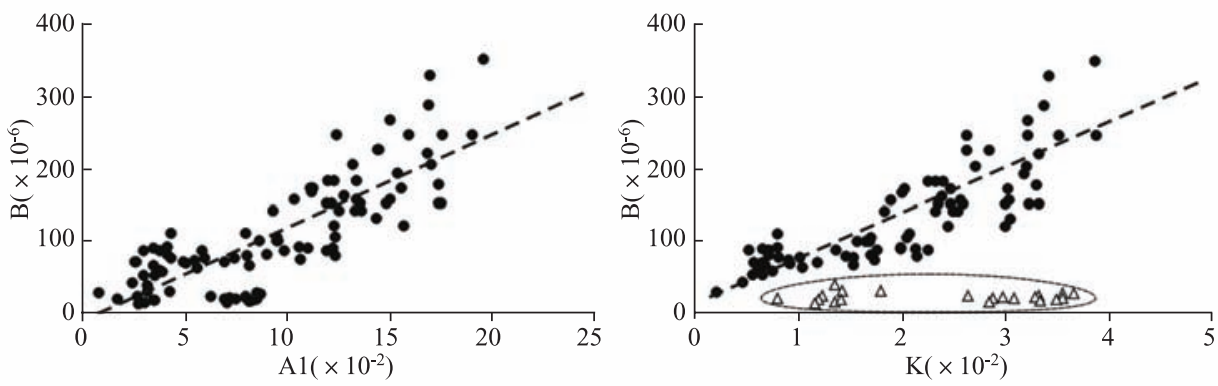

图 2 样品中 $\mathrm{B}$ 与 $\mathrm{Al} 、 \mathrm{~K}$ 含量变化关系

Fig.2 Relationships diagrams of boron against aluminum and potassium contents

在利用微量元素 B 含量计算古盐度的几种方法中，Walker 法不能提供具体的盐度值，只能通过相当 硼的计算划分出盐度的区间; Couch 的计算方法准确度高, 适用盐度范围广，但常因为需要测量岩石的粘 土含量以及粘土矿物的相对比例而受到限制. 分别采用 Walker法和 Landergren法分别了进行古盐度计算, 二者结果可以相互比较和效验.

图 3 是采样剖面古盐度参数变化曲线, 可见根据 “相当硼含量” 划分的盐度区间, 湖泊古盐度变化幅度 极大, 从淡水湖泊经咸水湖至超咸水盐湖都有出现. 根据 Landergren 方法计算的古盐度也与 Walker 方法 得出了类似的结果，特别值得注意的是，虽然这二种计算方法计算的盐度值在剖面局部层段有一些细微 的偏差，但二者反映的湖泊水体盐度分布区间、盐度升高或减低的变化趋势几乎完全一致.

湖泊水体盐度的变化, 不仅会反映在微量元素含量及比值的变化上, 也会反映在岩石类型和古生物 组合上. 因此，对沉积标志和古生物组合的研究，可以对古盐度计算结果的可靠性进行验证. 根据野外 观察和室内薄片鉴定结果, 采样剖面 55 层和 60 层见有灰黑色含轮藻化石的灰岩. 轮藻多数生活在深度 不大的淡水中, 少数生活于半咸水. 现生轮藻常栖居在 $\mathrm{pH}$ 值为 5.2-9.8 之间的水体中, 而大多数生活在 $\mathrm{pH}$ 值约为 8.3 的碱性水体中. 这与计算得出的这二层石灰岩沉积于低盐度环境的结论相吻合. 另外, 采 样剖面石膏层可以为我们判别古盐度提供另外一个验证标志. 石膏开始沉淀时水体的盐度要比正常海水 盐度高 3.55 倍, 盐度为 $115 \%$, 这也是超咸水中白云石沉淀向盐水环境中石膏沉淀过渡时的临界盐度. 采 
样剖面中与盐湖相石膏共生的泥岩层位计算的古盐度都进人了超盐度或盐湖环境，超过 Landergren 法取 得的盐度为 $115 \%$ 这一界线, 说明通过样品嗍元素含量估算的古盐度具有一定的可信度，可以作为一个 指示古环境变化的有效指标.

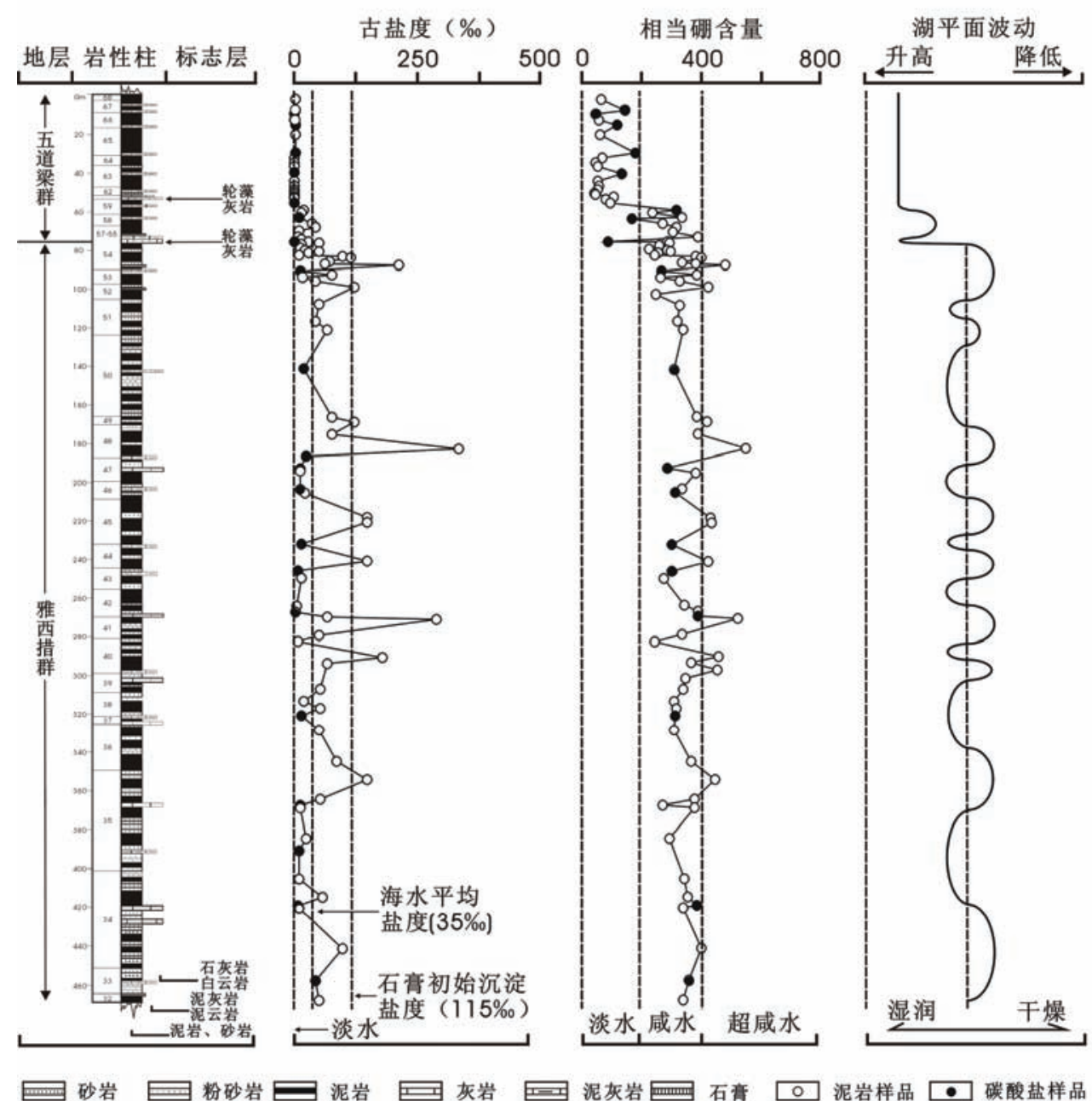

图 3 通天河剖面古盐度和湖平面垂向变化曲线

Fig.3 The vertical curves of paleo-salinity and lake level in the Tongtianhe section

\section{3 湖平面变化过程重建}

湖水盐度或矿化度是湖泊水文化学属性之一, 是用来表征单位水体内盐含量的一个指标, 它可直接 反映出湖水的化学类型. 通常根据湖水矿化度(含盐度)将湖泊分为淡水湖、咸水湖和盐湖三类, 即矿化度 小于 $1.0 \mathrm{~g} / \mathrm{L}$ 的湖泊称为淡水湖, 矿化度在 $1.0-35.0 \mathrm{~g} / \mathrm{L}$ 之间的湖泊称咸水湖, 矿化度大于 $35.0 \mathrm{~g} / \mathrm{L}$ 的湖泊 称为盐湖.

干旱地区或半干旱地区的封闭湖泊，一般在湖水高水位时，由于降雨量和径流量增加，湖水含盐度 降低; 当蒸发量超过人湖水量时, 湖水水位下降, 湖水浓缩、含盐度随之升高. 应用这个关系, 在湖相沉 积剖面横坐标取湖水盐度值, 划分为淡水、微咸水、咸水、超咸水和盐水湖 5 个区间, 纵坐标表示样品 位置，古盐度投影点之间以曲线相连，并结合盐度变化的峰值、转换点、演变趋势进行圆滑处理，就可以 定性地编绘出湖平面变化曲线. 
图 3 是重建的通天河剖面晚渐新世-早中新世古盐度和古湖面变化曲线. 可以发现, 研究区雅西措组 上部古湖泊水体的盐度一般处于咸水湖分布区，盐度变化于微咸水到超咸水范围内，局部出现盐湖环境. 由于气候偏干，水体蒸发量常大于降水量，以出现蒸发浓缩成因的白云岩、石膏沉淀为标志，指示湖平面 长期处于低水位期. 同时, 周期性降水量或人湖水量的增加，造成湖面上升、水体盐度减低，在湖相沉积 剖面上形成了一系列淡化-咸化旋回, 在长周期低水位的背景上出现叠加了多个低幅度湖面上升期. 这 与孢粉植物群研究得出的青藏地区渐新世时期气候以干热为主的特点比较一致 ${ }^{[20]}$.

研究区五道梁组下部以高湖面淡水湖泊为主体, 出现以黑灰色轮藻灰岩以及灰绿色泥灰岩为标志的 低盐度淡水湖泊. 反映高原北部气候向湿润方向发展，湖平面上升进入高水位泛湖期，过去分隔的湖泊 之间相互贯通 ${ }^{[13,21]}$. 但由雅西措顶部过渡到五道粱组底部则出现淡水湖与咸水型的频繁交替, 湖水盐度 剧烈变化. 在古盐度和复原的湖平面变化曲线上, 显示一个明显的拐点, 记录了一次重要的水文和水化 学事件. 渐新世与中新世界线附近湖平面快速变化的特点可能反映了极端干旱与湿润气候期的快速交替, 也可以解释为当时气候由冷干向暖干转型, 由于气温上升、冰雪融化、人湖水量突然增加造成湖水淡化 的结果.

\section{4 结语}

近年来, 湖泊沉积的研究愈来愈受到重视, 这是因为, 湖泊沉积物具有连续性好、信息量大、时间分 辨率高、地理覆盖面广的特点, 被认为是研究过去气候和环境演化历史的信息库, 具有其它自然记录如 树轮、冰芯、黄土等无法替代的优势 ${ }^{[22]}$.

湖面变化是气候变化对湖泊影响过程的直观体现，它具有对气候及自然环境变化的指示意义. 在湿润 区开放湖泊体系, 湖水水量平衡受地表和地下水体的注人及外泄的影响, 湖水盐度变化与湖平面升降的关 联不明显. 但地处干旱、半干旱地区的封闭湖泊体系, 气候变化是影响水文要素变化的主导因素, 湖水水量 和水化学对降水和蒸发的变化十分敏感, 湖泊水文状况和水化学性质往往可以反映流域水量平衡关系, 进 而推论区域降水量和蒸发量变化, 尤其是湖泊水位的同步变化可以指示区域气候格局和强度的变化.

封闭湖泊一般人湖水量小于湖面蒸发量, 是内陆湖泊的一个特殊类型, 但分布广泛, 在热带、温带和 寒冷区都有出现. 从现代湖泊群的地理分布来看, 封闭湖泊多位于不同自然地带的过渡带, 是地理环境 变化的敏感区，因此其湖面波动指示相邻自然地带的迁移，能反映全球性气候的变化. 在重建古代湖泊 沉积记录的湖面波动曲线时, 可以应用湖相碳酸盐沉积物中 $\delta^{18} \mathrm{O}$ 和 $\delta^{13} \mathrm{C}$ 之间的关系作为判别湖泊类型的 标志 ${ }^{[23-24]}$. Talbot 和 $\mathrm{Li}$ 等提出 ${ }^{[25-26]}$, 在开放型淡水湖泊中, 湖水停留时间短, 湖相碳酸盐岩 $\delta^{18} \mathrm{O}$ 变化范围 小, 几乎为一常数, $\delta^{18} \mathrm{O}$ 和 $\delta^{13} \mathrm{C}$ 之间无明显的相关性. 而在封闭型咸水湖环境中, 湖相碳酸盐岩的 $\delta^{18} \mathrm{O}$ 和 $\delta^{13} \mathrm{C}$ 之间呈明显的同步相关变化，封闭性越强，湖水滞留时间愈长，则相关系数越大.

泥质岩在湖泊沉积区分布广泛，且在剖面层序中有时序连续的特点. 利用泥岩硼元素法恢复古盐度, 己经做过充分的研究并得到了成功的应用, 证明了利用该方法可以有效地推算过去湖水盐度, 结合其它 一些指标如沉积磷酸盐法、介壳壳体 $\mathrm{Sr} / \mathrm{Ca}$ 法、碳酸盐碳氧同位素等交互验证，则可以建立高分辨率湖 平面变化曲线. 但是, 通过沉积记录提取古盐度参数重建古代湖平面变化序列, 其应用会受到如下要素 的影响：(1)在湿润气候区由于盐度变化幅度小, 湖平面变化与湖水盐度之间相关性不明显, 该方法难于 适用. 而在极端干旱的条件下, 湖泊干枯消亡也将造成湖平面记录的缺失; (2)盐度指示湖平面变化的理 论依据建立在单一湖泊演化的基础上，因此湖面波动周期和分辨率将在很大程度上取决于湖泊生存的持 续时间; (3)构造运动和局部地形变动可以造成湖泊消亡，中断湖平面变化的连续记录，在地层间断面、侵 蚀面上下湖平面变化曲线出现拐点. (4)半干旱一半湿润气候条件下, 具有一定面积的浅水湖泊对气候变 化最敏感, 它们甚少受到局部因素的干扰, 而深水湖泊可能会因为湖水盐度分层使得利用盐度变化指示 湖平面波动周期发生畸变，在陆缘近海湖中，通过海道侵进的海水也可以造成湖水盐度升高.

\section{5 参考文献}

[1] Street-Perrott FA, Harrison SP. Lake levels and climate reconstruction. In: Hecht AD ed. Paleoclimate analysis and modeling. 
New York: John Wiley, 1985: 291-340.

[2] Harrison SP, Yu Ge, Tarasov PE. Late Quaternary lake-level record from northern Eurasia. Quaternary Research, 1996, 45: $138-159$.

[3] 于 革, 王苏民. 欧亚大陆湖泊记录和两万年来大气环流变化. 第四纪研究, 1998, (4): 360-367.

[4] 丁永建, 刘时银, 叶柏生等. 近 50a 中国寒区与早区湖泊变化的气候因素分析. 冰川冻土, 2006, 28(5): 623-632.

[5] 伊海生, 张小青, 朱迎堂. 㒸塘地区中部湖泊岩芯记录的第四纪湖面变化及气候意义. 地学前缘, 2006, 13(5): 300-307.

[6] 李栓科. 中昆仑山区封闭湖泊湖面波动及其气候意义. 湖泊科学, 1992, 4(1): 19-30.

[7] 柏春广，穆桂金. 艾比湖的湖岸地貌及其反映的湖面变化. 干旱区地理, 1999, 22(1): 34-40.

[8] 贾玉连, 施雅风, 范云崎. 四万年以来青海湖的三期高湖面及其降水量研究. 湖泊科学, 2000, 12(3): 211-218.

[9] 齐 文, 郑绵平. 西藏扎布耶盐湖 $30.0 \mathrm{KaBP}$ 以来水位与古降水量变化. 地球学报, 2005, 26(1): 53-60.

[10] 孙占东, 姜加虎, 王 润. 岱海水盐变化原因及影响研究. 干旱区研究, 2006, 23(2): 264-268.

[11] 李 忡, 马 魏, 史晓新等. 呼伦湖水位、盐度变化(1961-2002 年). 湖泊科学, 2006, 18(1): 13-20.

[12] 曹建廷, 段学军, 王苏民等. 近 800a 来内蒙古岱海湖水的盐度定量及其气候意义. 地学前缘, 2002, 9(1): 187-192.

[13] Yi Haisheng, Wang Chengshan, Liu Sun et al. Sedimentary record of the planation surface in the Hoh Xil region of the northern Tibet plateau. Acta Geologic Sinica, 2000, 74: 827-835.

[14] Wang Chengshan, Liu Zhifei, Yi Haisheng et al. Teriary crustal shortening and peneplanation in the Hoh Xil region: Implications for tectonic history of the northern Tibetan plateau. Journal of Asian Earth Science, 2002, 20: 211-223.

[15] 刘志飞, 王成善, 金 玮等. 青藏高原沱沱河盆地渐新-中新世沉积环境分析. 沉积学报, 2005, 23(2): 210-218.

[16] Lendergren S, Carvajal MC. Geochemistry of boron. III. The relationship between boron concentration in marine clay sediments and the salinity of the depositional environments expressed as an adsorption isotherm. Arkiv Mineralogioch Geologi $B d, 1969$, 5: 13-22.

[17] Walker CT, Price NB. Departure curves for computing paleosalinity from boron in illities and shales. AAPG Bull, 1963, 47(5): 833-841.

[18] Walker CT. Evaluation of boron as a paleosalinity indicator and its application to offshore prospects. $A A P G B u l l, 1968, \mathbf{5 2}(5)$ : 751-766.

[19] Couch EL. Calculation of paleosalinity from boron and clay mineral data. AAPG Bull, 1971, 55: 1829-1839.

[20] 刘东生, 郑绵平, 郭正堂等. 亚洲季风系统的起源和发展及其与两极冰盖和区域构造运动的时代耦合性. 第四纪研究, 1998, (3): 194-204.

[21] 吴珍汉, 吴中海, 胡道功等. 青藏高原腹地中新世早期古大湖的特征及其构造意义. 地质通报, 2006, 25(7): 782-791.

[22] 李玉成, 王苏民, 黄耀生. 气候环境变化的湖泊沉积学响应. 地球科学进展, 1999, 14(4): 412-416.

[23] 伊海生，林金辉，周恳恳等. 青藏高原北部新生代湖相碳酸盐岩的碳氧同位素特征及古环境意义. 古地理学报，2007, 9(3): 303-312.

[24] 伊海生, 林金辉, 周恳恳等. 可可西里地区中新世湖相叠层石成因及其古气候意义. 矿物岩石, 2008, 28(1): 106-113.

[25] Talbot MR. A review of the palaeohydrological interpretation of carbon and oxygen isotopic ratios in primary lacustrine carbonates. Chemical Geology, 1990, 81: 261-279.

[26] Li HC, Ku TL. $\delta^{13} \mathrm{C}-\delta^{18} \mathrm{O}$ covariance as a paleohydrological indicator for closed-basin lakes. Palaeogeography Palaeoclimatology Palaeoecology, 1997, 133: 69-80 